\title{
Prevalence and Predictor of Exclusive Breastfeeding among Mothers of 0 to 6 months Infants from Pastoralists and Hunters' Community in Tanzania; A Community Based Cross-Sectional Study
}

\author{
Fabiola Vincent Moshia*, Esther E. Akyoob, Saada Ally Seifa \\ aDepartment of Nursing Management and Education, School of Nursing and Public Health of University of Dodoma, Tanzania, bDepartment of \\ Clinical Nursing, School of Nursing and Public Health of University of Dodoma \\ Correspondence to Fabiola V Moshi, (fabiola.moshi@gmail.com)
}

\begin{abstract}
Background: Initiating breastfeeding during the first hour after birth and continuing breastfeeding exclusively for 6 months prevents childhood infections such as diarrhoea. Exclusive breastfeeding (EBF) for the first 6 months of life of the baby is recognised globally as the best and the most effective intervention to ensure the survival of babies. The aim of this study was to determine the prevalence of EBF and its predictors among mothers of 0 to 6 months infants from pastoralists and hunters' community in Manyara region-Tanzania.

Methods: This was a community-based analytical cross-sectional study that involved 342 mothers of 0 to 6 months infants who were randomly selected through 4 stage multistage sampling technique. Data was collected using an intervieweradministered questionnaire. Collected data was analysed using Statistical Package for Social Sciences (SPSS) version 20. Binary Logistic Regression analysis was used to establish factors associated with EBF practices.

Results: The prevalence of EBF among postnatal women from hunters and pastoralists societies was $47.1 \%$ at $95 \%$ $\mathrm{Cl}=41.7 \%-52.5 \%$. After adjusted for confounders, the predictors of EBF practice were age of infants $10-1$ months, $A O R=$ 2.838 at $95 \% \mathrm{Cl}=1.326-6.075, p=.007)$, age of mothers $(26-35$ years, $\mathrm{AOR}=1.851$ at $95 \% \mathrm{Cl}=1.059-3.234$, $p=.031$ ), Level of education of infants' mothers (primary education, $\mathrm{AOR}=2.374$ at $95 \% \mathrm{Cl}=1.321-4.265, p=.004$ ) and knowledge on exclusive breast feeding, $\mathrm{AOR}=2.51$ at $95 \% \mathrm{Cl}=1.435-4.393, p=.001$.

Conclusion: Majority of mothers from pastoralists' and hunters' societies were not practising EBF. Predictors of EBF practice were; the age of infants, maternal age, level of education of the mother and knowledge on exclusive breastfeeding. Poor EBF practice was mainly contributed to low level of knowledge about the EBF. The low level of knowledge could have been contributed by poor access to maternal services. Nature of living (lack of permanent settlement) of the study population could have contributed to low access to maternal services. An innovative interventional study is highly recommended to come up with strategies that will improve knowledge on EBF and practice of EBF
\end{abstract}

\section{BACKGROUND}

Child mortality remains a public health challenge $\mathcal{C}$ globally. It is estimated that $70 \%$ of deaths that occurred between the ages of 0-25 years in 2019 were costly comprised of children below 5 years, amounting to 5.2 Million deaths. The first month of life was the riskiest period for child survival as $47 \%$ of below 5 deaths occurred in this period. $28 \%$ of below 5 death occurred among children aged 1-11 Months. ${ }^{1}$

Exclusive Breast Feeding (EBF) for the first 6 months of the life of the baby is recognised globally as the best and most effective intervention to ensure the survival of babies. ${ }^{2}$ Globally, about $35 \%$ of babies are breastfed exclusively, whereas in sub-Saharan Africa, babies who are breastfed exclusively range between $22 \%$ and $33 \% .^{3}$
How infant feeding is done in the first 6 months is diverse and is based on geographical, economical and cultural settings whereby the main concern is the time when mothers initiate breastfeeding, complementary breastfeeding, duration of breastfeeding and the age at which mothers wean their infants. ${ }^{4}$ A study conducted in the United States of America (USA) reveals that practicing EBF for not less than the first 6 months can stop over 900 deaths of infants and children which occur yearly in the USA. ${ }^{5}$

The prevalence of EBF of babies from birth to 6 months has however increased among developing countries from 33\% in the year 1995 to $39 \%$ in the year 2010 and the West and Central Africa have shown much improvement. ${ }^{6}$ Despite so many studies having been conducted on EBF, the practice is still not extensive in 
developing countries and is still far beyond the global expectation of $90 \%$, which leaves a gap for much betterment. Furthermore, the associated factors can be quite different between one country and another or even within the same country. ${ }^{7}$ In a study conducted in Baghdad, exclusive Breastfeeding is reported to have the ability to decrease the risk of lower respiratory infections. The study further states that the infants who are provided with formula feeding have a 2.7 times risk for Acute Respiratory Infection (ARI) compared to breastfed infants while those infants breastfed for less than 3 months have a 2.5 times risk for ARI. ${ }^{8}$

Milk from a woman's breasts boosts sensory and cognitive maturity and protects the baby from common childhood illnesses and chronic illnesses as well as shortening the time to recover from illness. ${ }^{9}$ Studies have also indicated that breast milk prevents metabolic diseases especially against obesity and type 2 diabetes mellitus. ${ }^{10}$ Early initiation of complementary foods and liquids decrease the amount of breast milk the infant takes and thus reducing the absorption of the necessary nutrients found in breast milk, hence increasing the chances for the infant to acquire ARI and diarrhoea. ${ }^{11}$ Other studies have shown that EBF is associated with a reduced risk of HIV infection from mother to child. ${ }^{12}$

Milk from a woman's breasts is the only food derived from nature that a baby requires for the first 6 months of life. Breast milk is easily digestible and absorbable, provides the baby with all nutrients and contains digestive enzymes. Infants who are breastfed exclusively for 6 months tend to develop a high IQ, less risk for developing childhood obesity and are also protected against childhood diseases. ${ }^{13}$ EBF is protective against otitis media. ${ }^{14}$ EBF also has benefits for the mother whereby; it increases hormone production which helps in the uterine contractions preventing postpartum haemorrhage. It also acts as natural contraception as it delays the time for fertility, reduces the risk for ovarian and breast cancer while promoting bond for both mother and child. ${ }^{15}$

In Tanzania, the EBF rate is still low, at about 59\% compared to the global target of $90 \%$, however initiating breastfeeding during the first hour after delivery is at $51 \%{ }^{16}$. In the locality of Manyara Region, the EBF is still very low compared to the national level with prevalence of $33.3 \%$ according to Tanzania National Nutritional Survey $^{17}$, whereby initiating breastfeeding during the first hour after delivery is reported to be $76 \% .{ }^{16}$ In Zanzibar, although mothers have good knowledge of breastfeeding practices, many did not practice EBF and the reported rate of EBF was $20.8 \% .{ }^{18}$ This can be explained with the existing challenges for meeting exclusive breastfeeding such as the belief that breast milk alone is not sufficient in meeting babies' nutritional needs, short maternity leave and socio-cultural pressure to introduce water and artificial feeds. ${ }^{19}$

Previous studies have listed several factors associated with exclusive breastfeeding such as ethnicity of the mother $^{20}$, maternal education ${ }^{20,21}$, family income ${ }^{20}$, perceived inadequate breast milk ${ }^{21}$, maternal age ${ }^{22}$, mode of delivery ${ }^{21}$ and knowledge about EBF. ${ }^{23}$

Despite the sensitisation through media, drama on EBF - practice, still suboptimal breastfeeding is existing in theManyara region where the majority of the habitant population are hunters and pastoralists. Little is known on predictors of EBF practices among indigenous pastoralists and hunters' communities in the Manyara region.

\section{METHODS}

\section{Research Design}

This study was a community-based cross-sectional analytical study that involved assessing the exposure and outcomes ofEBF and predictors of EBF practice.

\section{Study Area}

This study was conducted in rural areas of the Manyara region in 3 districts namely; Mbulu, Simanjiro, and Hanang. This Region is located in the Great Rift Valley and has large herds of cattle and wildlife reserves. It is home for the most distinctive indigenous tribes. The Hadzabe tribe who live in Yaeda Chini valley practice hunting and collecting of wild honey, roots and wild fruits. Other tribes found in the region are; Iraqw, Gorowa, Maasai, Barbaig/ Mang'ati. ${ }^{24}$ In a report from the 2012 National Census, the region has a population of 1,425,131 people. Among these, females are $708,046 .{ }^{25}$ The region has 10 hospitals, 25 health centres and 207 dispensaries. Similar to other regions, the numbers of health facilities do not match the population, also, the region has an additional barrier towards accessing maternal health services. The majority of hunters and pastoralists do not have permanent settlements as they migrate depending on the availability of pasture. The majority of rural dwellers in Tanzania depend very much on health facilities as their sole source of health education.

\section{Study Population}

The study population included all mothers from pastoralists and hunters' community together with their infants of 0 to 6 months of age in the 3 selected districts within the Manyara region.

\section{Inclusion Criteria}

Postnatal mothers with infants aged 0 to 6 months from hunters and pastoralists societies who consented to participate in the study.

\section{Exclusion criteria}

Postnatal mothers with infants aged 0-6 months from hunters and pastoralists societies who were very sick, mentally sick and those with infants who were very sick.

\section{Sample Size Estimation}

This study used the proportion of $33.3 \%$ of women practicing EBF in the Manyara Region as reported in the Tanzania National Nutrition Survey.

The formula used was adopted from Cochran, 1975 $\mathrm{n}=\underline{\mathrm{Z}^{2}} \underline{\underline{\mathrm{pq}}} \underline{\mathrm{e}^{2}}$

Where;

$\mathrm{n}=$ minimal sample size desired

$\mathrm{p}=$ proportion of the target population estimated to be exclusively breastfed $33.3 \%$

$\mathrm{q}=\mathrm{l}-\mathrm{p}$

$\mathrm{e}=$ marginal error $5 \%$

$\mathrm{Z}=$ standard normal deviation at, 95\% confidence inter- 
val 1.96

$$
\begin{gathered}
n=1.96^{2} \times 0.333(1-0.333) \\
n=323.5 \approx 324
\end{gathered}
$$

The computed figure 324 was adjusted by 10\% for the inconsistencies and incompleteness. The sample size arrived at was 356 participants

\section{Sampling Technique}

Manyara Region was selected purposively because it showed a low prevalence of EBF $(33.3 \%)$ as reported in the Tanzania National Nutrition Survey ${ }^{17}$. It is also the home for pastoralists and hunters community. The study employed the multistage sampling technique. This involved 4 stages:

First stage: Selection of Districts: 3 districts out of 5 districts in the Manyara region were randomly selected using Simple Random Sampling by Lottery Selection.

Second stage: Selection of Wards: Simple Random Sampling by Lottery method was employed to select 2 wards out of 8 wards in each district, making a total of 6 wards.

Third stage: Selection of Villages: On each of the selected ward, 3 villages out of 4 was selected using Simple Random Sampling by Lottery method, making a total of 18 villages. Each ward in Tanzania contains approximately 4 villages. ${ }^{25}$

Fourth stage: Selection of Household: After obtaining a list of households with infants from the community health care workers' register, 19 households out of approximately 34 households were selected using Simple Random Sampling from each of the 18 villages.

\section{Data Collection Method}

Data was collected using interviewer-administered questionnaires and documentary reviews. 5 research assistants were recruited and trained about the tool and data collection process. The principal investigator and the research assistants were fluent in 3 languages; English, Swahili and the local language of the interviewee. The tool was developed in English and translated into Swahili. The questionnaire was then translated to specific local languages to facilitate easy capture of the data. Documentary review involved analysing Reproductive and Child Health $(\mathrm{RCH})$ cards which were obtained from mothers. The instrument was piloted among unselected villagers in Manyara Region and minor modifications were done before the final document of the tool was released. Data was collected from 8th April 2019 to $6^{\text {th }}$ June 2019.

\section{Variables}

Independent variables were maternal characteristics and socio-cultural factors. The dependent variable was prevalence and predictors of EBF

\section{Variable Measurement}

EBF practice was measured by using close-ended questionnaires with 7 selected items each having I mark for the correct answer and 0 score for incorrect answer. Before Principal Component Factor (PCA), analysis was done to extract the items, one item was excluded since it had the same response (yes). On the first phase of PCA, the variance was 33.694 and all remaining 6 items werabove 0.3 . Mean was 0.86 , median 0.97 , minimum 2.48 and maximum was 2.85976. Since data was not normally distributed, median was used as a cut-point for categorisation. Participants who scored below-median were considered as non-EBF mothers while those scoring above the median were considered as EBF mothers.

Maternal knowledge of EBF was measured by 22 items. Each right answer had I mark and the wrong answer had a zero mark, making a total of 22 (100\%). Principle Factor Analysis was employed to extract items. Among 22 items, 2 items carried the same value (yes) for all respondents so they were excluded during data processing.

In the first phase of Principle Factor Reduction analysis, 20 items were included and the highest variance was 25.737, then 2 items were again excluded because they had a weighted score of $<0.3$. During the $2^{\text {nd }}$ phase of Factor Reduction, 18 items were selected, the highest variance was 31.011 . All the remaining 18 items scored more than 0.3, therefore these items were used for scoring. Normality test showed that data was normally distributed. Therefore, mean was selected to be the cut point for scoring. Mean $=0.49$, median $=0.27$, ode $=2.72$, SD 1.14, minimum -1.75 , maximum $=2.72$. Those who scored above the mean had adequate knowledge, and those who scored below mean had inadequate knowledge.

\section{Data Analysis}

Data was first checked for completeness and missing information and then manually cleaned before it was analysed using Statistical Package for Social Sciences (SPSS) version 20 developed by IBM USA. Demographic characteristics were analysed by Descriptive Statistics to indicate frequencies and percentages. Frequencies were recorded in charts, which showed the prevalence and magnitude of the selected variables. A normality test was used to test the distribution by histogram. To assess the level of knowledge of EBF and practices of breastfeeding among respondents, Principal factor analysis was employed to determine the scores.

A chi-square test was used to test the relationship between maternal variables and EBF practices. Maternal variables with a p-value less than 0.2 in the Chi-square test were entered into a regression model to establish the association. Binary Logistic regression was used to determine the strength of association between the selected variables controlling for confounder variables whereby both Odds Ratio (OR) and Adjusted Odds Ratio (AOR) were reported. Significance level was set to $0.05(P<.05)$ equivalent to $95 \%$ Confidence Interval.

\section{Ethics Approval and Consent to Participate}

The proposal was approved by the Ethical Review Committee of the University of Dodoma in Dodoma, Tanzania Ref: UDOM/DRP/134/VOL VII/36. Furthermore, a letter of permission was obtained from the Manyara Region Administration. Both written and verbal consents were sought from study participants after explaining to them the study objectives, procedures and their right to refuse to participate in the study at any time they wish. For study participants who were younger than 18 years, verbal consent to participate was sought from their parents or guardians. 


\section{RESULTS \\ Socio-Demographic Characteristics of the Infants Aged 0-6 Months and their Mothers}

Of the 356 sampled mothers, the response rate was $96 \%$ which is equivalent to 342 mothers.

The majority, 155(45.3\%) of infant mothers were in the age group of $16-25$ years with mean $27.59 \pm 6.498$. Nearly half, $164(48 \%)$ of the study respondents had no formal education. The majority of infants were aged between 4-5 months $130(38.0 \%)$. The mean age of the infants was $2.76 \pm 1.023$. Most of the infants, $227(66.4 \%)$ were male and most of them $222(64.9 \%)$ had good progress in immunisation according to schedule (Table 1).

\section{Prevalence of Exclusive Breasiffeeding Practice}

The results of this study show that more than half of the respondents $181(52.9 \%)$ were not practicing EBF while only $161(47.1 \%)$ were practicing EBF. The prevalence of EBF practice was $47.1 \%$ and $95 \% \mathrm{CI}=41.7 \%-52.5 \%$

\section{Maternal Knowledge of EBF}

In general, among all the study respondents, only $147(43.0 \%)$ had adequate knowledge of exclusive breastfeeding

\section{The Relationship between Socio-Demographic Characteris- tics and EBF}

Socio-demographic characteristics which showed a significant relationship with EBF were the age of the infant $(p<.001)$, age group of infants' mothers $(p=.026)$, Mother's level of education $(p<.001)$, mother's occupation $(p=.022)$, Religion $(p=.005)$, mothers' knowledge about EBF $(p<.001)$ and the number of antenatal visits $(p<.001)$ (Table 2)

When adjusting for confounders, knowledge on EBF was found to be a strong predictor of EBF. Those with adequate knowledge on EBF were nearly 3 times more likely to have good breastfeeding practices compared to those with inadequate knowledge, $\mathrm{AOR}=2.51$ at $95 \%$ $\mathrm{CI}=1.435-4.393, p=.001$, age of infants ( 6 months, AOR= 2.838 at $95 \%$ CI $=1.326-6.075, p=.007)$, age of mothers $(26-35$ years, $\mathrm{AOR}=1.851$ at $95 \% \mathrm{CI}=1.059-3.234$, $p=.031$ ) and level of education of infants' mothers (primary education, $\mathrm{AOR}=2.374$ at $95 \% \mathrm{CI}=1.321-4.265$, $p=.004$ ) (Table 3).

\section{DISCUSSION}

In the current study, the prevalence of EBF among mothers of infants aged 0-6 months from pastoralists and hunters' communities in the Manyara Region was low $(42.4 \%)$ if compared to the national average of EBF of $59 \% .^{22}$ A higher prevalence of EBF has been reported by a similar study done in Kigoma Tanzania. ${ }^{27}$ The reason for the difference could be due to differences in study settings. The current study was done among rural communities while the study in Kigoma was among urban dwellers. The low prevalence could be due to cultural factors and the nature of lifestyle of this community. A previous study done in Kenya has reported that socio-cultural beliefs (considering colostrum as 'dirty, a curse, bad omen, associated with breastfeeding while engaging in extramarital affairs, a fear of the 'evil eye' when breastfeeding in public) play suboptimal roles in EBF practice. ${ }^{28}$
The hunters and pastoralists do lack permanent settlements, they move according to the availability of pasture and food. For such a lifestyle, it becomes hard for them to access maternal health services where they could access health education on EBF.

The findings from the current study showed that the EBF prevalence $(42.4 \%)$ was higher compared to the previous study by Tanzania National Nutrition Survey which reported the EBF in Manyara region to be $33.3 \%{ }^{17}$. This increase could be because of the time that has passed since the survey was conducted and women may have acquired some knowledge since several media sensitise people about of importance EBF. These results were compared to findings from previous studies in Ghana, where it was reported that the EBF practice was $66.0 \%$, Manhean et al. $^{29}$, this is higher than the current study. The difference could be due to differences in sample characteristics and knowledge the mothers had on EBF and methods used for data collection. Meanwhile, a study in Bangladesh reported that EBF practices were at 35.90\%. ${ }^{30}$ However, the findings from another study in Ethiopia ${ }^{31}$ reported EBF practice of $44.2 \%$ which was in contrast to the current study. Furthermore, a study which was conducted in rural Coast region Tanzania reported EBF practice to be at about $30 \% .{ }^{32}$ However, a study conducted in Muheza reported EBF practice to be $24.1 \%$. $^{3}$ This difference in results could be due to the difference in sample size which was used and geographical location.

The study found that maternal knowledge about EBF significantly influenced their practice on EBF. Postnatal mothers who had adequate knowledge of EBF were almost 3 times more likely to practice Exclusive Breastfeeding when compared with those with inadequate knowledge. This means, knowledge of EBF plays an optimal role in EBF practice. Similar previous studies conducted elsewhere have also reported significant association between knowledge on EBF and EBF practice. ${ }^{33,34}$

In the current study, only $45.9 \%$ of postnatal mothers had adequate knowledge of EBF. The reason for inadequate knowledge of EBF could be that women in this community have low level of education. Secondly, because they move from place to place grazing livestock, they have little time to attend ANC from where they could get knowledge of EBF. Another reason could be due to the language used to provide health education during maternal services visits at health centres, the majority of women of this community could only understand messages spoken in their local languages while the medium of communication in health facilities is Swahili.

In contrast, a similar study in Nigeria reported low knowledge of EBF where only $30.0 \%$ of women were adequately informed. ${ }^{34}$ However, in a study conducted in Ghana among rural lactating mothers, $74 \%$ had general knowledge of EBF which they got from health care providers during antenatal and postnatal visits. ${ }^{35}$

In Malawi, the rate of EBF among babies below 6 months of age increased from 3\% in 1992 to $71 \%$ in 2010 . This was attributed to the government's implementation of the Infant and Young Child Feeding (IYCF) program as well as enrolment of a mass education program to increase support and EBF knowledge. ${ }^{11}$ 
TABLE 1: Socio-Demographic Characteristics of the Infant and Mother ( $N=342)$

\begin{tabular}{|c|c|c|}
\hline Variable & Frequency (n) & Percentage (\%) \\
\hline \multicolumn{3}{|c|}{ The age group of infant mothers } \\
\hline $16-25$ years & 155 & 45.3 \\
\hline $26-35$ years & 137 & 40.1 \\
\hline $36-45$ years & 50 & 14.6 \\
\hline \multicolumn{3}{|l|}{ Education of infant mothers } \\
\hline None & 164 & 48.0 \\
\hline Primary & 154 & 45.0 \\
\hline Secondary/higher & 24 & 7.0 \\
\hline \multicolumn{3}{|c|}{ Marital status of infant mothers } \\
\hline Married/cohabiting & 317 & 92.7 \\
\hline Unmarried & 25 & 7.3 \\
\hline \multicolumn{3}{|c|}{ Occupation of the infant-mother } \\
\hline Livestock keeper & 151 & 44.2 \\
\hline Hunter & 54 & 15.8 \\
\hline Peasants & 103 & 30.1 \\
\hline Employed /Self-employed & 34 & 9.9 \\
\hline \multicolumn{3}{|l|}{ Tribe of the infant-mother } \\
\hline Maasai & 102 & 29.8 \\
\hline Barbaiq/Mang'ati & 86 & 25.1 \\
\hline Iraqw & 79 & 23.1 \\
\hline Hadzabe & 52 & 15.2 \\
\hline Other tribes & 19 & 5.6 \\
\hline Ndorobo/Akea & 4 & 1.2 \\
\hline \multicolumn{3}{|l|}{ The religion of infant-mother } \\
\hline Traditional & 168 & 49.1 \\
\hline Christians & 163 & 47.7 \\
\hline Muslims & 11 & 3.2 \\
\hline \multicolumn{3}{|l|}{ District of residence } \\
\hline Mbulu & 119 & 34.8 \\
\hline Hanang & 113 & 33.0 \\
\hline Simanjiro & 110 & 32.2 \\
\hline \multicolumn{3}{|l|}{ Toilet available } \\
\hline Yes & 326 & 95.3 \\
\hline No & 16 & 4.7 \\
\hline \multicolumn{3}{|l|}{ Safe water available } \\
\hline Safe & 98 & 28.7 \\
\hline Unsafe & 244 & 71.3 \\
\hline \multicolumn{3}{|l|}{ Hygiene } \\
\hline Good & 304 & 88.9 \\
\hline Poor & 38 & 11.1 \\
\hline \multicolumn{3}{|l|}{ Parental smoking } \\
\hline Yes & 127 & 37.1 \\
\hline No & 215 & 62.9 \\
\hline \multicolumn{3}{|c|}{ The age group of infants (month) } \\
\hline $0-1$ & 55 & 16.1 \\
\hline $2-3$ & 65 & 19.0 \\
\hline $4-5$ & 130 & 38.0 \\
\hline 6 & 92 & 26.9 \\
\hline \multicolumn{3}{|l|}{ Sex } \\
\hline Boys & 227 & 66.4 \\
\hline Girls & 115 & 33.6 \\
\hline
\end{tabular}


TABLE 2: The Relationship between Socio-Demographic and EBF

\begin{tabular}{|c|c|c|c|c|}
\hline Variable & $\begin{array}{c}\operatorname{EBF}(n=145) \\
n(\%)\end{array}$ & $\begin{array}{l}\text { Mixed feeding }(n=197) \\
n(\%)\end{array}$ & $\mathrm{X} 2$ & P-value \\
\hline \multicolumn{5}{|l|}{ Age group of infants } \\
\hline 0 to 1 month & $22(40)$ & $33(60)$ & \multirow{4}{*}{20.423} & \multirow{4}{*}{$<.001$} \\
\hline 2 to 3 months & $36(55.4)$ & $29(44.6)$ & & \\
\hline 4 to 5 months & $45(34.6)$ & $85(65.4)$ & & \\
\hline 6 months & $58(63)$ & $34(37)$ & & \\
\hline \multicolumn{5}{|l|}{ Sex of a child } \\
\hline male & $104(45.8)$ & $123(54.2)$ & & \\
\hline female & $57(49.6)$ & $58(50.4)$ & .431 & .512 \\
\hline \multicolumn{5}{|l|}{ The age group of mothers } \\
\hline $16-25$ years & $71(45.8)$ & $84(54.2)$ & \multirow{3}{*}{7.309} & \multirow{3}{*}{.026} \\
\hline $26-35$ years & $74(54)$ & $63(46)$ & & \\
\hline $36-45$ years & $16(32)$ & $34(68)$ & & \\
\hline \multicolumn{5}{|l|}{ Level of Education of mother } \\
\hline no formal education & $54(32.9)$ & $110(67.1)$ & \multirow{3}{*}{25.798} & \multirow{3}{*}{$<.001$} \\
\hline primary education & $91(59.1)$ & $63(40.9)$ & & \\
\hline secondary /higher education & $16(66.7)$ & $8(33.3)$ & & \\
\hline \multicolumn{5}{|l|}{ Occupation of a mother } \\
\hline peasant & $49(47.6)$ & $54(52.4)$ & \multirow{4}{*}{9.620} & \multirow{4}{*}{.022} \\
\hline employed/self-employed & $22(64.7)$ & $12(35.3)$ & & \\
\hline livestock keeping & $73(48.3)$ & $78(51.7)$ & & \\
\hline hunting & $17(31.5)$ & $37(68.5)$ & & \\
\hline \multicolumn{5}{|l|}{ Marital status } \\
\hline Married/cohabiting & $153(48.3)$ & $164(51.7)$ & \multirow[b]{2}{*}{2.461} & \multirow[b]{2}{*}{.117} \\
\hline Not married & $8(32)$ & $17(68)$ & & \\
\hline \multicolumn{5}{|l|}{ Tribe } \\
\hline Iraqw & $39(49.4)$ & $40(50.6)$ & \multirow{6}{*}{11.002} & \multirow{6}{*}{.051} \\
\hline Barbaiq & $43(50)$ & $43(50)$ & & \\
\hline Hadzabe & $17(32.7)$ & $35(67.3)$ & & \\
\hline Maasai & $47(46.1)$ & $55(53.9)$ & & \\
\hline Ndorobo & $1(25)$ & $3(75)$ & & \\
\hline Others & $14(73.7)$ & $5(26.3)$ & & \\
\hline \multicolumn{5}{|l|}{ Religion } \\
\hline Christian & $88(54)$ & $75(46)$ & \multirow{3}{*}{10.772} & \multirow{3}{*}{.005} \\
\hline Muslim & $8(72.7)$ & $3(27.3)$ & & \\
\hline Traditional/pagan & $65(38.7)$ & $103(61.3)$ & & \\
\hline \multicolumn{5}{|l|}{ Parity } \\
\hline Primipara & $62(43.7)$ & $80(56.3)$ & & \\
\hline Multipara & $99(49.5)$ & $101(50.5)$ & 1.136 & .287 \\
\hline Number of ANC Visits & & & & \\
\hline None & $29(27.1)$ & $78(72.9)$ & & \\
\hline One-three & $79(52)$ & $73(48)$ & 27.976 & $<.001$ \\
\hline Four or more & $53(63.9)$ & $30(36.1)$ & & \\
\hline $\begin{array}{l}\text { Place of Childbirth } \\
\text { Health Facility }\end{array}$ & $82(412)$ & 117158 & & \\
\hline $\begin{array}{l}\text { Health Facullty } \\
\text { Traditional Birth attendants }\end{array}$ & $\begin{array}{l}82(41.2) \\
99(69.2)\end{array}$ & $44(30.8)$ & 26.230 & $<.001$ \\
\hline Knowledge about EBF & & & & \\
\hline Adequate & $103(65.6)$ & $54(34.4)$ & & \\
\hline Inadequate & $58(31.4)$ & $127(68.6)$ & 39.995 & $<.001$ \\
\hline
\end{tabular}

The study also found that the age of the infant influenced EBF practice. Postnatal mothers with neonates were almost 3 times more likely to practice EBF compared to postnatal mothers with infants aged 6 months and above.
The reason for this could be due to the belief that breast milk alone cannot meet the nutritional requirements of older infants. Also, this could be due to maternal engagement in household activities which may sometimes 
TABLE 3: Predictors of Exclusive Breastfeeding (EBF) ( $N=342)$

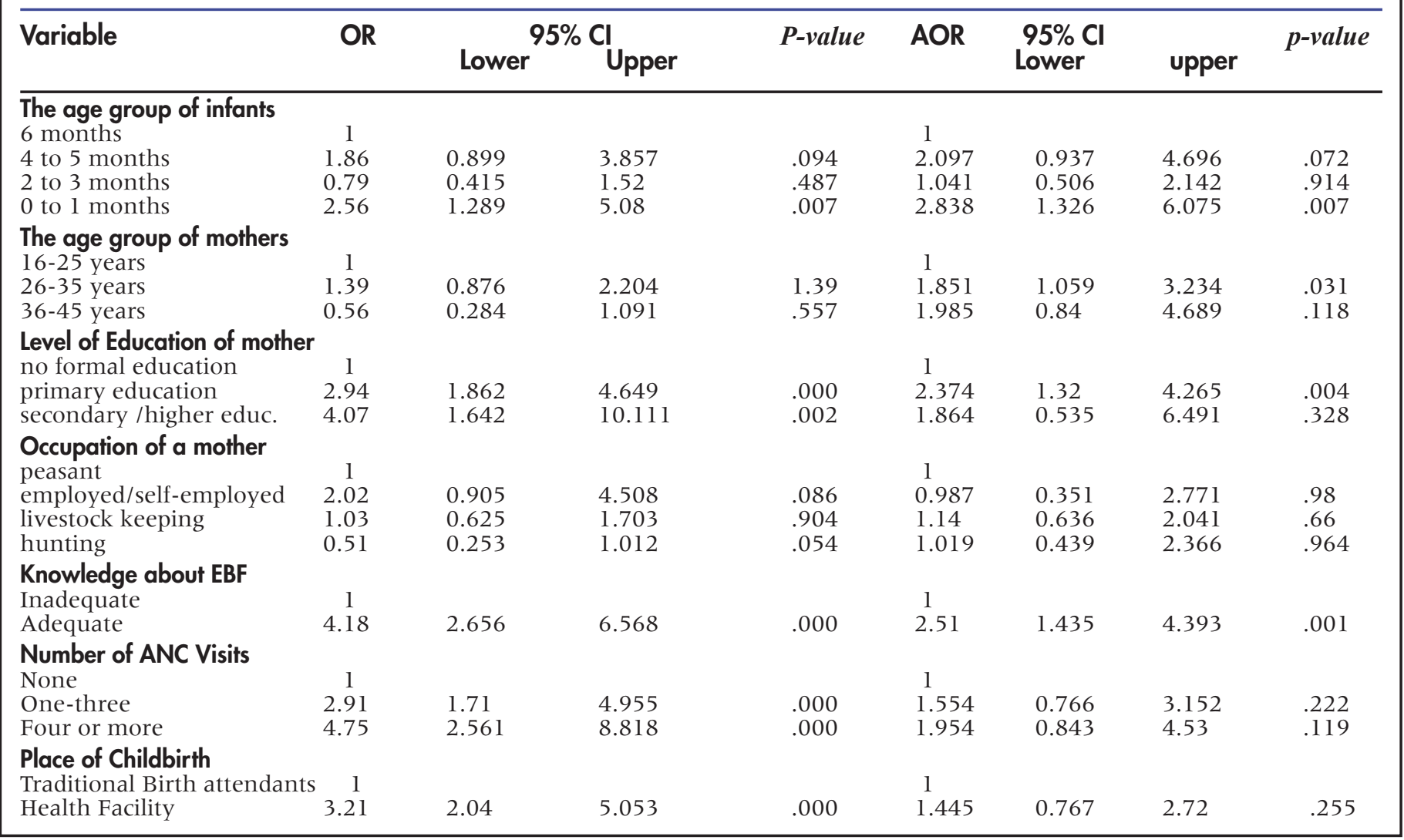

necessitate separation with the infant for hours. Similar previous studies on predictors of EBF have reported similar findings. ${ }^{19,33}$

The study also found that maternal level of education predicted significantly EBF practice. Postnatal mothers who had primary education were twice more likely to practice EBF compared to postnatal mothers with no formal education. A previous study conducted in Northern Tanzania on predictors of EBF practice reported a different finding that women's level of education does not predict the practice of EBF. ${ }^{3}$ Different findings could be due to differences in the study communities. In the current study, language barrier could have played a great role in hindering acquisition of knowledge on EBF. Postnatal mothers who attended primary level of education have the advantage of learning the Swahili Language, the language used in the delivery of maternal health services, including health education in health centres. This factor could have favoured them to acquire adequate knowledge on EBF which in turn facilitated the practice of EBF. The current study also found that maternal age predicted the practice of EBF. Postnatal mothers with advanced age were twice more likely to practice EBF than young postnatal mothers. The finding is in line with a similar previous study conducted in Northern Tanzania. ${ }^{3}$ Another study conducted in Zimbabwe has reported maternal age of below 25 years as a barrier towards EBF practice.

\section{Study Limitations}

The key information gathered from the study participants was self-reported which is subject to under-or over-reporting. Despite the systematic data collection approach, there may have been some intrinsic bias in the questionnaire or manner in which questions were asked that might have affected the responses. Although the reported predictors were controlled through regression analysis, the causal-effect relationship study is recommended.

\section{CONCLUSIONS}

The EBF practice is poor in the Manyara region. Postnatal mothers who were more likely to practice EBF were those of advanced age, with infants aged 0-1 months, had a primary level of education and had an adequate level of knowledge on EBF. The study recommends an innovative interventional study to come up with cost-effective strategies to improve EBF practice among hunters and pastoralists communities, specifically, to address their knowledge on EBF as the vast majority of them had inadequate knowledge on EBF.

Acknowledgement: The authors thank the University of Dodoma for providing ethical clearance for this study. We are grateful to the administration of the Manyara Region for allowing us to conduct the study and to each of the study participants for their participation in this study. 


\section{REFERENCES}

1. Unicef. Levels \& Trends in Child Mortality [Internet]. 2020. Available from: https://www.unicef.org/media/79371/file/ UN-IGME-child-mortality-report-2020.pdf.pdf

2. Indongo N, Mutorwa K. The Practice of Exclusive Breastfeeding in Namibia International Journal of Sciences: The Practice of Exclusive Breastfeeding in Namibia. 2017;(September).

3. Maonga AR, Mahande MJ, Damian DJ, Msuya SE. Factors Affecting Exclusive Breastfeeding among Women in Muheza District Tanga Northeastern Tanzania: A Mixed Method Community Based Study. Matern Child Health J. 2016;20(1):77-87. doi: 10.1007/s 10995-015-1805-z. Medline

4. Li R, Perrine CG, Scanlon KS. Prevalence and Reasons for Introducing Infants Early to Solid Foods: Variations by Milk Feeding Type. 2013;

5. Scherbaum V. The Role of Breastfeeding in the Prevention of Childhood Malnutrition. 2016;(August).

6. Cai X, Wardlaw T, Brown DW. Global trends in exclusive breastfeeding. 2012;2-6. Available from: https://internationalbreastfeedingjournal. biomedcentral.com/track/pdf/10.1186/17464358-7-12.pdf

7. WHO. Indicators for assessing infant and young child feeding practices. 2010; Available from: https://www.who.int/nutrition/publications/infantfeeding/9789241599290/en/

8. Al-sharbatti SS, Aljumaa LI. Infant feeding patterns and risk of acute respiratory infections in Baghdad/Traq. 2012;9(3): 1-9.

9. Gertosio C, Meazza C, Pagani S, Bozzola M. Breastfeeding and its gamut of benefits. 2014;147(2): 135-40. Available from: https://www. researchgate. net/publication/303431896_ Breastfeeding_and_its_gamut_of_benefits

10. Savino F, Sorrenti M. Advances on human milk hormones and protection against obesity. 2013;(November).

11. WHO/UNICEF. Global Nutrion Target 2025.Breastfeeding Policy Brief.WHO/MNH/NHD 14.7. 2012;8. Available from:https: / / www. who.int/nutrition/publications/globaltargets2025_policybrief_breastfeeding/en/

12. WHO. Guideline Updates on HIV and Infant Feeding. Who Publ [Internet]. 20 16;59. Available from: https://www.who.int/maternal_child_adolescent/documents/hiv-infant-feeding-2016/ en/

13. Eidelman Al. Breastfeeding and the Use of Human Milk: An Analysis of the American Academy of Pediatrics 2012 Breastfeeding Policy Statement. 2012;7(5):323-4.

14. Abrahams SW, Labbok MH. Breastfeeding and Otitis Media A Review of Recent Evidence Breastfeeding and Otitis Media: A Review of Recent Evidence. 2014;(May).

15. Fairbrother N, Stanger-ross I. Reproductive-Aged Women's Knowledge and Attitudes Regarding Infant-Feeding Practices : An Experimental Evaluation Reproductive-Aged Women's Knowledge and Attitudes Regarding Infant-Feeding Practices: An Experimental Evaluation. 2016;(December 2009).

16. National Bureau of Statistics. Tanzania Demographic and Health Survey and Malaria Indicator Survey (TDHS-MIS) 2015 16. 2016. p. 172-3.

17. MoHSW. Ministry of Health and Social Welfare Tanzania National Nutrition Survey 2014. 2014;(November).

18. North A, Khamis AG, Omar AM, Suleiman SA, Ali FS. Prevalence of Exclusive Breastfeeding and its Predictors among mothers in Clinics in Mother and Child Health. 2017;14(1):1-9.

19. Diji AKA, Bam V, Asante E, Lomotey AY, Yeboah S, Owusu HA. Challenges and predictors of exclusive breastfeeding among mot- thers attending the child welfare clinic at a regional hospital in Ghana: a descriptive cross-sectional study. Int Breastfeed J. 2016;12(1):13. doi: 10.1186/s 1 3006-0 17-0104-2. Medline

20. Odar Stough C, Khalsa AS, Nabors LA, Merianos AL, Peugh J. Predictors of Exclusive Breastfeeding for 6 Months in a National Sample of US Children. Am J Health Promot. 2019;33(1):48-56. doi: $10.1177 / 0890117118774208$. Medline

21. Kasahun AW, Wako WG, Gebere MW, Neima GH. Predictors of exclusive breastfeeding duration among 6-12 month aged children in gurage zone, South Ethiopia: a survival analysis. Int Breastfeed J. 2016;12(1):20. doi:10.1186/s13006-0170107-z. Medline

22. Dede KS, Bras H. Exclusive breastfeeding patterns in Tanzania: Do individual, household, or community factors matter? Int Breastfeed J. 2020; 15(1):32. doi: 10.1186/s 1 3006-020-00279-8. Medline

23. Sonko A, Worku A. Prevalence and predictors of exclusive breastfeeding for the first six months of life among women in $\mathrm{Hal}$ aba special woreda, Southern Nations, Nationalities and Peoples' Region/SNNPR/, Ethiopia: a community based cross-sectional study. Arch Public Health. 2015;73(1):53. doi: 10.1186/ s1 3690-01 5-0098-4. Medline

24. IFAD. United Republic of Tanzania Country Technical Note on Indigenous Peoples' Issues. Popul Policy Compend. 1980: 1-6. https://www.ifad.org/en/web/knowledge/-/publication/tanzania-country-technical-note-on-indigenous-peoples-issues

25. National Bureau of Statistics (NBS), Office of Chief Government Statistician (OCGS). Population Distribution by Age and Sex: The United Republic of Tanzania. 2013;471. Available from: http:// ihi.eprints.org/2169/1/Age_Sex_Distribution.pdf

26. Ajay S, Micah B. Sampling techniques \& determination of sampke sizein applied statistics research: An overview. 2014;1/(1 1): 122.

27. Nkala TE, Msuya SE. Prevalence and predictors of exclusive breastfeeding among women in Kigoma region, Western Tanzania: a community based cross- sectional study. $2011 ; 1-7$.

28. Wanjohi M, Griffiths P, Wekesah F, et al. Sociocultural factors influencing breastfeeding practices in two slums in Nairobi, Kenya. Int Breastfeed J. 2016;1 2(1):5. doi:10.1 186/s 1 3006-0160092-7. Medline

29. Manhean T, Asare BY, Preko JV, Baafi D, Dwumfour-asare B. Breastfeeding practices and determinants of exclusive breastfeeding in a cross- sectional study at a child welfare clinic in. $2018 ; 1-9$.

30. Hossain M, Islam A, Kamarul T, Hossain G. Exclusive breastfeeding practice during first six months of an infant 's life in Bangladesh : a country based cross-sectional study. 2018;1-9.

31 . Elyas L, Mekasha A, Admasie A, Assefa E. Exclusive Breastfeeding Practice and Associated Factors among Mothers Attending Private Pediatric and Child Clinics, Addis Ababa, Ethiopia: A Cross-Sectional Study. 2017;2017.

32. Kazaura M. Exclusive breastfeeding practices in the coast region Tanzania. 2016; Available from: https://www.ncbi.nlm.nih. gov/pmc/articles/PMC4915437/pdf/AFHS 1601-0044.pdf

33. Egata G. Prevalence of Exclusive Breast Feeding and its Predictors Among Infants Aged Six Months in Jimma Town, Southwest Ethiopia, 2013. Journal of Pediatrics \& Neonatal Care. $2014 ; 1(3): 1-6$. doi:10.15406/ipnc.2014.01.00017

34. Mo O, As $U$, Ahmed $H$. Knowledge and practice of exclusive breastfeeding in Kware, Nigeria. 2016;(September).

35. Mogre V, Dery M, Gaa PK. Knowledge, attitudes and determinants of exclusive breastfeeding practice among Ghana ian rural 
lactating mothers. Int Breastfeed J. 2016;1 111):12. doi:10.1186/ s13006-0 16-0071-z. Medline

\section{Peer Reviewed}

Competing Interests: None declared.

Funding: This study did not receive any funding

Received: 29 April 2020; Accepted: 04 June 2021

Cite this article as Moshi VF, Akyoo EE, Seif AS. Prevalence and Predictor of Exclusive Breastfeeding among Mothers of 0 to 6 months Infants from Pastoralists and Hunters' Community in Tanzania; A Community Based Cross-Sectional Study. East Afr Health Res J. 2021;5(1):82-90. https://doi.org/10.24248/eahrj. $\underline{\mathrm{v} 5 \mathrm{il} .655}$

() Moshi et al. This is an open-access article distributed under the terms of the Creative Commons Attribution License, which permits unrestricted use, distribution, and reproduction in any medium, provided the original author and source are properly cited. To view a copy of the license, visit http://creativecommons.org/licenses/by/4.0/. When linking to this article, please use the following permanent link: https://doi.org/10.24248/ eahrj.v5il.655 